\title{
Effect of Electric Field on Aging Phase Transformation in Al-Zn-Mg-Cu Alloys
}

\author{
Chun-Mei LI1,a, Zhong-Jing XIE,b, Zhi-Qian CHEN1,c, Xiao LI11,d, Hong HE and \\ Nan-Pu CHENG 1 ,e, ${ }^{*}$
}

1. Faculty of Materials and Energy, Southwest University, Chongqing 400715, China

alcm1998@swu.edu.cn, bxzjlms13@swu.edu.cn, cChen_zq@swu.edu.cn, d|x123ppp@swu.edu.cn,

eCheng_np@swu.edu.cn

${ }^{*}$ Corresponding author, cheng_np@swu.edu.cn

Keywords: Aging phase transformation, Electric field, First-principles, Al-Zn-Mg-Cu alloys

\begin{abstract}
The effect of electric fields on the aging phase transformation of Al-Zn-Mg-Cu alloys is investigated with the first-principles method combined with vacancy mechanism. The effects of external electric field with different direction on aging phase transformation and electron structure are analyzed. Results show that the Gibbs free energy of the $\eta$ ' phase exhibits different responses to the different external electric directions. The orientation precipitation of the $\eta$ ' phase can be activated during aging with an external electric field lower than $26 \mathrm{MV} / \mathrm{cm}$. The calculation of density of states provides an explanation for the different responses of the GP zones, $\eta^{\prime}$ and $\eta$ phases to the external electric field. And a vacancy mechanism is proposed to explain the microstructural evolution during aging in an electric field.
\end{abstract}

\section{Introduction}

Experimental evidence for the effects of electric fields on precipitates have been provided by previous studies[1-4]. Conrad pointed out that an externally applied electric field could reduce both the volume fraction and density of cavities during the plastic deformation of aluminum alloy 7475, and result in improved post-deformation strength and ductility[1]. Zhou et al. found that the electric field led to coarser grain boundaries combined with finer and more uniformly dispersed precipitates in matrix, which resulted in higher fatigue crack propagation resistance during aging[2]. The experimental results show that external electric field can be used to control the alloy's microstructure. However, most of the observed phenomena were explained based merely on the influence of the electric field on the vacancies[5-7]. The influence of an electric field on thermodynamic properties has received minimal attention[8].

In this study, the effect of electric field on aging phase transformation in $\mathrm{Al}-\mathrm{Zn}-\mathrm{Mg}-\mathrm{Cu}$ alloys is analyzed by using first-principles calculations. This method has been successfully used to analyze the effect of electric field on the electronic and optical properties of nanoparticles, the phase transformation of Ti-Rh alloy, and alloying solid solution strengthening of Fe-Ga alloys[9-11].

Phase transformations are determined by the principles of thermodynamics and kinetics[12]. In thermodynamics, the minimum Gibbs free energy specifies which phase is stable at a particular condition and determines the direction of phase transformation[13]. Additionally, from the viewpoint of kinetics, electric fields can modify phase transformations by enhancing the atomic diffusivity of phases, for instance, their influence on diffusion-controlled transformations such as age-hardening of aluminum alloys[1]. 


\section{Theory and Methodology}

The results of vibrational analysis or Hessian evaluation have been utilized to compute enthalpy $(\mathrm{H})$, entropy (S), and free energy $(G)$ as functions of temperature[14,15]. In this work, the energy at 0K is counted as zero because the absolute value of the energies at $0 \mathrm{~K}$ is meaningless for the analysis of the effect of external electric field. The change of the relative value of energy is determinative and concerned with the phase transformation.

Enthalpy correction $H$ is provided by

$$
H(T)=E_{\mathrm{vib}}(T)+E_{\text {rot }}(T)+E_{\text {trans }}(T)+R T
$$

where the subscripts represent the vibrational, rotational, and translational contributions, and $\mathrm{R}$ is the ideal gas constant. The contributions are provided by

$$
\begin{aligned}
& \left.E_{\text {trans }}=3 R T / 2 \quad \text { (for } Q_{\text {trans }}=\sum_{i} \frac{\sqrt{2 \pi M k T / N_{\mathrm{a}}}}{h}\right) \\
& E_{\text {rot }}(\text { linear })=R T \quad\left(\text { for } Q_{\text {rot }}(\text { linear })=\frac{8 \pi^{2} I k T}{\sigma h^{2}}\right) \\
& E_{\text {rot }}(\text { nonlinear })=3 R T / 2 \quad\left(\text { for } Q_{\text {rot }}(\text { nonlinear })=\left(\frac{\sqrt{\pi}}{\sigma}\right)\left[\frac{8 \pi^{2} k T}{h^{2}}\right]^{3 / 2} \sqrt{I_{\mathrm{A}} I_{\mathrm{B}} I_{\mathrm{C}}}\right) \\
& E_{\mathrm{vib}}=\frac{R}{k} \frac{1}{2} \sum_{i} h v_{i}+\frac{R}{k} \sum_{i} \frac{h v_{i} \exp \left(-h v_{i} / k T\right)}{\left[1-\exp \left(-h v_{i} / k T\right)\right]} \quad\left(\text { f or } \quad Q_{\mathrm{vib}}=\sum_{i} \frac{1}{\left[1-\exp \left(-h v_{i} / k T\right)\right]}\right)
\end{aligned}
$$

where $\mathrm{Q}_{\mathrm{vib}}, \mathrm{Q}_{\mathrm{rot}}, \mathrm{Q}_{\text {trans }}$ are the partition function for $\mathrm{E}_{\mathrm{vib}}, \mathrm{E}_{\mathrm{rot}}$ and $\mathrm{E}_{\text {trans }} . k$ is the Boltzmann's constant, $\mathrm{h}$ the Planck's constant, and $v_{\mathrm{i}}$ the individual vibrational frequencies, $\sigma$ is symmetry number, $\mathrm{I}$ is moment of inertia, $\mathrm{I}_{\mathrm{A}}, \mathrm{I}_{\mathrm{B}}$, and $\mathrm{I}_{\mathrm{C}}$ are moments of inertia of $\mathrm{A}, \mathrm{B}$, and $\mathrm{C}$ axes, $\mathrm{M}$ is the molecular weight. ( $E_{\text {rot }}\left(\right.$ linear) and $E_{\text {rot }}$ (nonlinear) are used for linear and nonlinear systems, respectively. )

The contributions to entropy S are provided by

$$
\begin{aligned}
& S_{\text {tra }}=\frac{5}{2} R \ln T+\frac{3}{2} R \ln M-R \ln p-2.31482 \\
& S_{\text {rot }}(\text { linear })=R \ln \left[\frac{8 \pi^{2} I k T}{\sigma h^{2}}\right]+R \\
& S_{\text {rot }}(\text { nonlinear })=\frac{R}{2} \ln \left[\frac{\pi}{\sqrt{\sigma}} \frac{8 \pi^{2} c l_{A}}{h} \frac{8 \pi^{2} c l_{B}}{h} \frac{8 \pi^{2} c l_{C}}{h}\left(\frac{k T}{h c}\right)^{3}\right]+\frac{3}{2} R \\
& S_{v i b}=R \sum_{i} \frac{h v_{i} / k T \exp \left(-h v_{i} / k T\right)}{1-\exp \left(-h v_{i} / k T\right)}+R \sum_{i} \ln \left[1-\exp \left(-h v_{i} / k T\right)\right]
\end{aligned}
$$

where the $S_{\text {vib }}, S_{\text {rot }}$ and $S_{\text {trans }}$ respectively represent the vibrational, rotational and translational contributions. Gibbs energy can be calculated by the equation 


$$
G=H-T S
$$

Thermodynamic performance at different temperatures and electric intensities is calculated with the Dmol3 module. A macro-canonical ensemble (NVT) is selected for the calculations of all structures. Time step is set to $1.0 \mathrm{fs}$, and total simulation time of $0.01 \mathrm{ps}$ is selected. The all-electron potential function is determined, and the electron wave function is performed with the double-number function with the d orbital.

\section{Results and Discussion}

\section{Crystal Structures of the Precipitates}

A generally accepted typical precipitation sequence in $\mathrm{Al}-\mathrm{Zn}-\mathrm{Mg}-\mathrm{Cu}$ alloy is: supersaturated solid solution (SSS) $\rightarrow$ Guinier-Preston (GP) zones $\rightarrow$ metastable phase $\eta^{\prime} \rightarrow$ stable phase $\eta[16-18]$. GP zones are coherent with the Al matrix, and GPI zone has an internal arrangement for the $\mathrm{Zn}$ and $\mathrm{Al} / \mathrm{Mg}$ atoms on the $\{110\}_{\mathrm{Al}}$ planes. GPII zone contains a Zn-rich layer on the $\{111\}$ planes of Al matrix, and expands along the $\left\langle 110>\right.$ direction of the Al lattice. The metastable phase $\eta^{\prime}$ is semi-coherent with the matrix, having parameters of $\mathrm{a}=0.496 \mathrm{~nm} \approx[211] / 2_{\mathrm{Al}}$ and $\mathrm{c}=1.40 \mathrm{~nm} \approx 2[111]_{\mathrm{Al}}[19-21]$. In this work, two of the most widely accepted structures of $\eta^{\prime} \mathrm{I}$ and $\eta^{\prime} \mathrm{II}$ have been constructed resulted from its uncertainty of structure[19,20]. Stable phase $\eta\left(\mathrm{MgZn}_{2} \mathrm{phase}\right)$ has a hexagonal structure with lattice parameters of $\mathrm{a}=0.5221 \mathrm{~nm}$ and $\mathrm{c}=0.8567 \mathrm{~nm}$ and is incoherent with the matrix[22-25]. Their structures are shown in Fig.1, with their parameters shown in Table 1.

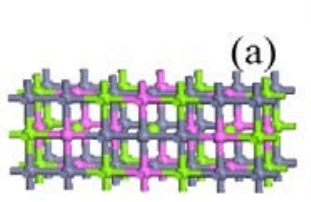

$\mathrm{Al}$

$$
\mathrm{Mg}
$$
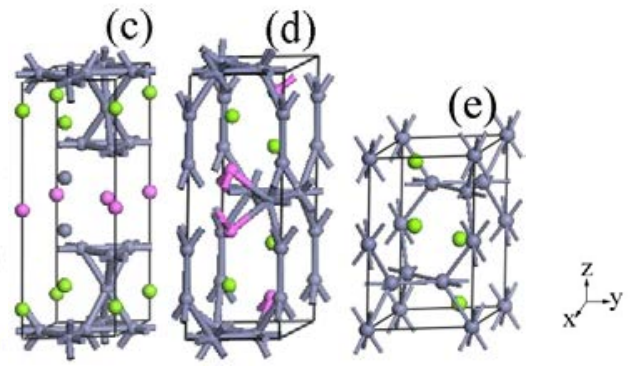

Fig. 1 Crystal structures of the calculated unit cells. (a) GP I , (b) GPII, (c,d) $\eta^{\prime}$ phase ( $\eta^{\prime}$ I , $\eta^{\prime}$ II), (e) $\eta$ phase.

\begin{tabular}{|c|c|c|c|c|c|c|c|c|}
\hline Phases & GP I & GP II & $\begin{array}{l}\text { Al1Mg4Z } \\
\text { n11 ( } \eta^{\prime} \text { I } \\
\text { phase) }\end{array}$ & $\begin{array}{l}\text { Al4Mg4Z } \\
\text { n10 ( } \eta^{\prime} \text { II } \\
\text { phase) }\end{array}$ & $\begin{array}{l}\eta^{\prime} \\
\text { (Exp.) }\end{array}$ & $\begin{array}{l}\operatorname{MgZn}_{2} \\
(\eta)\end{array}$ & $\begin{array}{l}\operatorname{MgZn}_{2} \\
\text { (Exp.) }\end{array}$ & $\begin{array}{l}\mathrm{MgZn}_{2} \\
\text { (Cal.) }\end{array}$ \\
\hline $\begin{array}{l}\text { Cryst. } \\
\text { Sys. }\end{array}$ & $\begin{array}{l}\text { tetrago } \\
\text { nal }\end{array}$ & $\begin{array}{l}\text { tetrago } \\
\text { nal }\end{array}$ & hexagonal & hexagonal & & $\begin{array}{l}\text { hexago } \\
\text { nal }\end{array}$ & & \\
\hline $\begin{array}{l}\text { Space } \\
\text { Group }\end{array}$ & $\begin{array}{l}\mathrm{I} 4 / \mathrm{mc} \\
\mathrm{m}\end{array}$ & $\begin{array}{l}\mathrm{I} 4 / \mathrm{mc} \\
\mathrm{m}\end{array}$ & P-6m2 & P-6 & & $\begin{array}{l}\mathrm{P} 63 / \mathrm{m} \\
\mathrm{mc}\end{array}$ & & \\
\hline$a(\AA)$ & 4.050 & 4.05 & $4.96[19]$ & $4.96[20]$ & $4.96[19]$ & 5.184 & $\begin{array}{l}5.21[22,23] \\
5.15[22,24]\end{array}$ & $5.223[25]$ \\
\hline$b(\AA)$ & 12.15 & 8.1 & $4.96[19]$ & $4.96[20]$ & $4.96[19]$ & 5.184 & $\begin{array}{l}5.21[22,23] \\
5.15[24]\end{array}$ & $5.223[25]$ \\
\hline$c(\AA)$ & 4.05 & 8.1 & $14.02[19]$ & $14.02[20]$ & $14.0[19]$ & 8.691 & $\begin{array}{l}8.60[26,27] \\
8.48[24]\end{array}$ & $8.566[25]$ \\
\hline$\alpha\left(^{\circ}\right)$ & 90 & 90 & 90 & 90 & 90 & 90 & 90 & \\
\hline $\overrightarrow{\beta\left(0^{\circ}\right)}$ & 90 & 90 & 90 & 90 & 90 & 90 & 90 & \\
\hline
\end{tabular}

Table 1. Lattice parameters of the calculated precipitates 


\begin{tabular}{|c|c|c|c|c|c|c|c|}
\hline$\gamma\left(0^{\circ}\right)$ & 90 & 90 & 120 & 120 & 120 & 120 & 120 \\
\hline$V\left(\AA^{3}\right)$ & & 265.7 & 298.7 & 298.7 & & 202.3 & $202.4[25]$ \\
\hline
\end{tabular}

\section{Effect of External Electric Field on Aging Phase Transformation}

The electric field with different directions may generate different effects on the free energy of the GP zones, $\eta^{\prime}$ and $\eta$ phases. The electric fields along the $[001]_{\mathrm{GPI}}$ and $[100]_{\mathrm{GPI}}$ directions almost do not change the Gibbs free energy of GPI, as shown in Figs. 2(a) and (c). What's more, the electric field along the $[010]_{\text {GPI }}$ direction slightly increases the Gibbs free energy of the GPI zone, as shown in Fig. 2(b). This finding means that the electric field along $[010]_{\mathrm{GPI}}$ direction hampers the precipitation of the GPI zone; the precipitation of the GPI zone with crystal orientation [010] along the electric field direction is restricted. For GP II, only a slight change in the Gibbs free energy is observed with the electric field direction along [100 $]_{\text {GP II }}$. The electric field along the other two directions decreases the Gibbs free energy of GP II with the electric intensity higher than 36.4MV/cm. From mentioned above, it can be concluded that with the electric field intensity lower than $26 \mathrm{MV} / \mathrm{cm}$, the differences of GP zones' free energy generated from electric fields in different directions are too small and can be ignored.

However, $\eta^{\prime}$ and $\eta$ phases show sensitive to the electric field direction among these five structures. Figs.2(i) and 2(l) show that the electric field lower than $26 \mathrm{MV} / \mathrm{cm}$ along the $[0001]_{\eta^{\prime}}$ crystal orientation causes an obvious decrease in the free energy of both $\eta^{\prime}$ I and $\eta^{\prime}$ II phases. However, the free energy only slightly decreases with electric fields lower than $26 \mathrm{MV} / \mathrm{cm}$ along the $[11-20]_{\eta^{\prime}}$ and $[1-100]_{\eta^{\prime}}$ crystal orientations. Thus in the condition that electric intensity is higher than $26 \mathrm{MV} / \mathrm{cm}$, the electric field is beneficial to the $\eta^{\prime}$ phase's precipitation with [11-20] $\eta_{\eta^{\prime}}$ and $[1-100]_{\eta^{\prime}}$ orientations along the electric field direction. For $\eta$ phase, its free energy shows little change with the applied electric field direction along the $[11-20]_{\eta}$ and $[1-100]_{\eta}$ crystal orientations in the whole scope of electric intensity. When the electric field direction is along [0001] $]_{\eta}$ crystal orientation, $\eta$ phase's free energy decreases with the electric intensity higher than $26 \mathrm{MV} / \mathrm{cm}$. So in order to improve the $\mathrm{Al}$ alloy's microstructure, the external electric intensity should be controlled lower than $26 \mathrm{MV} / \mathrm{cm}$, regardless of the direction of the electric field.
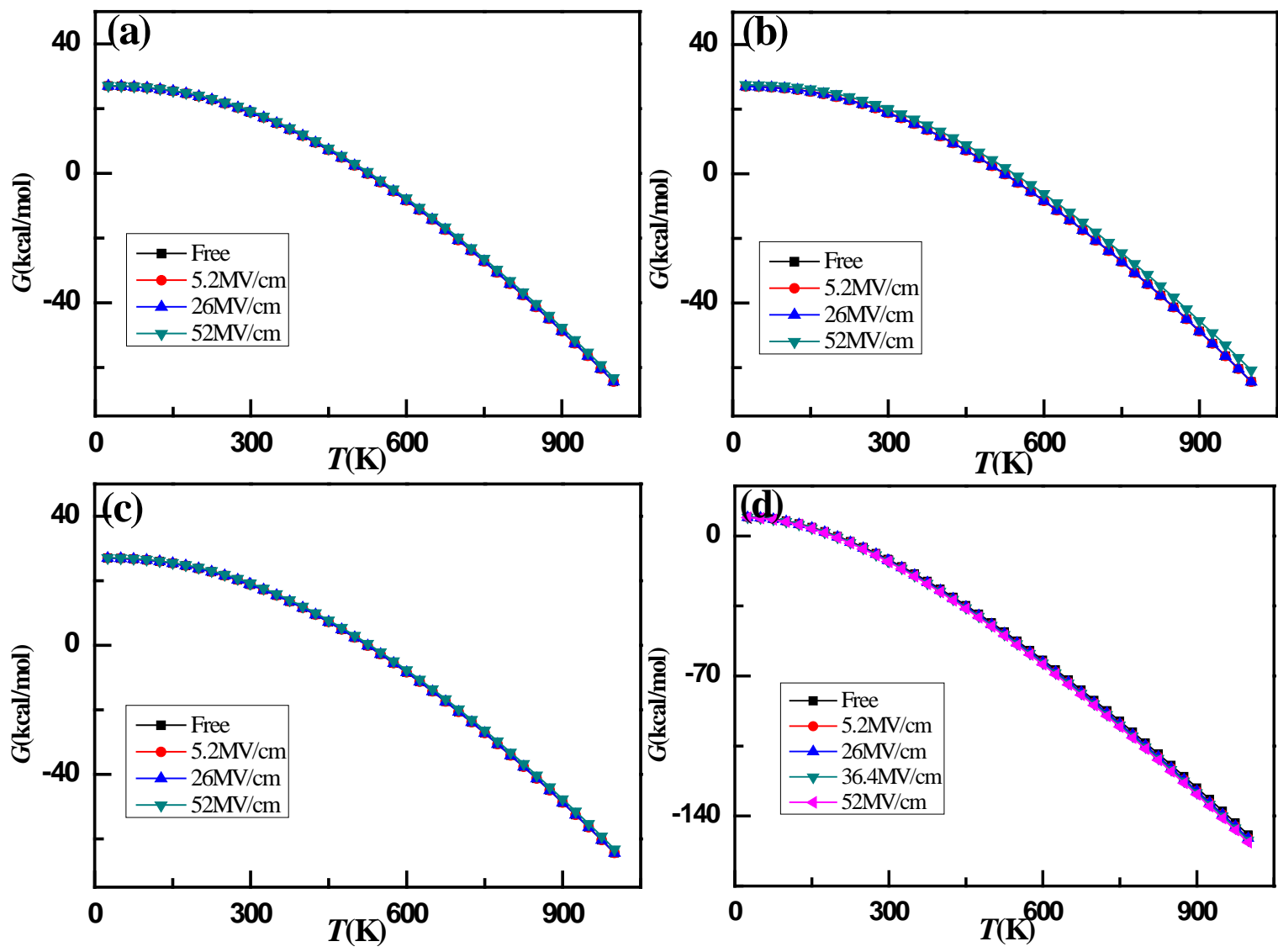

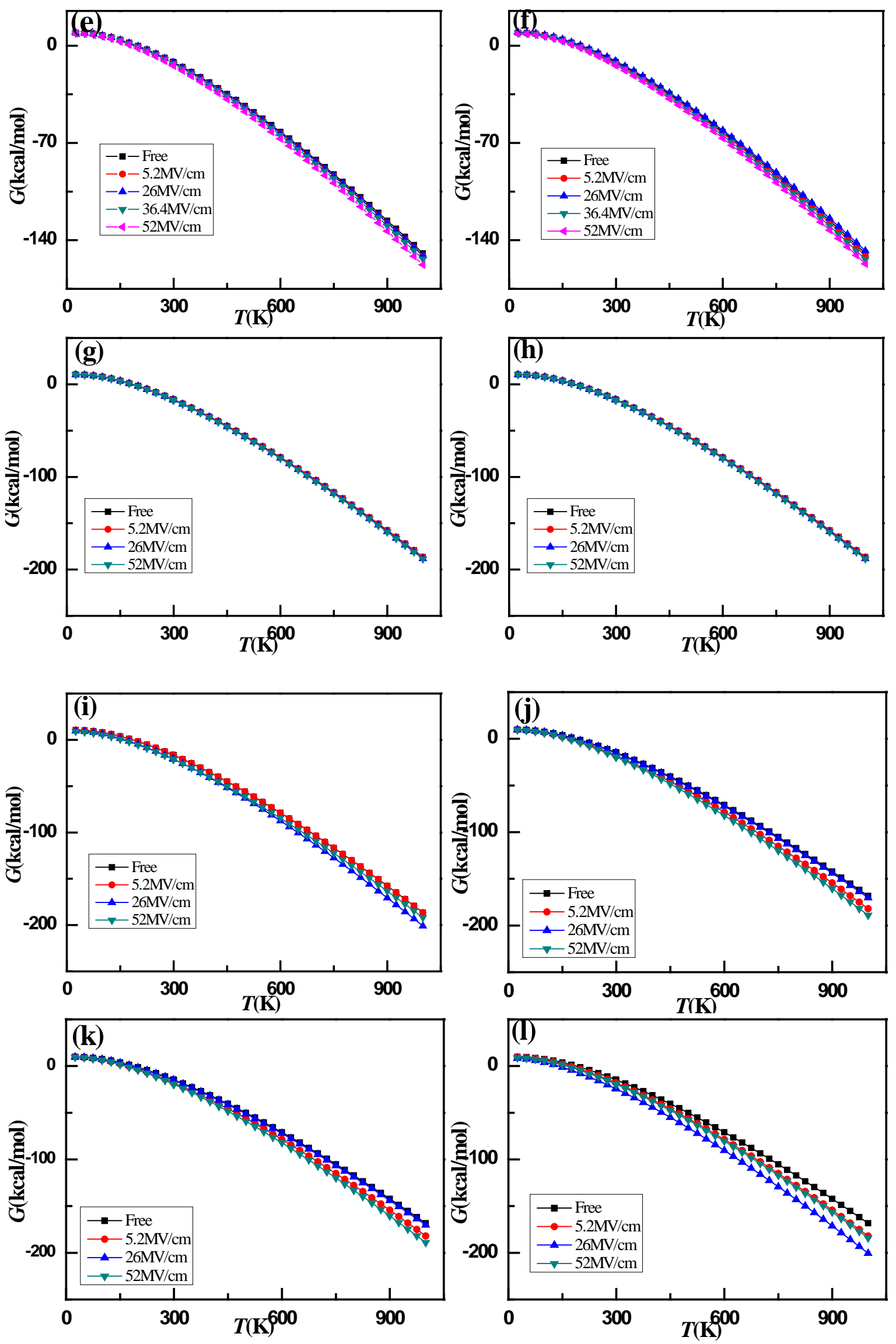

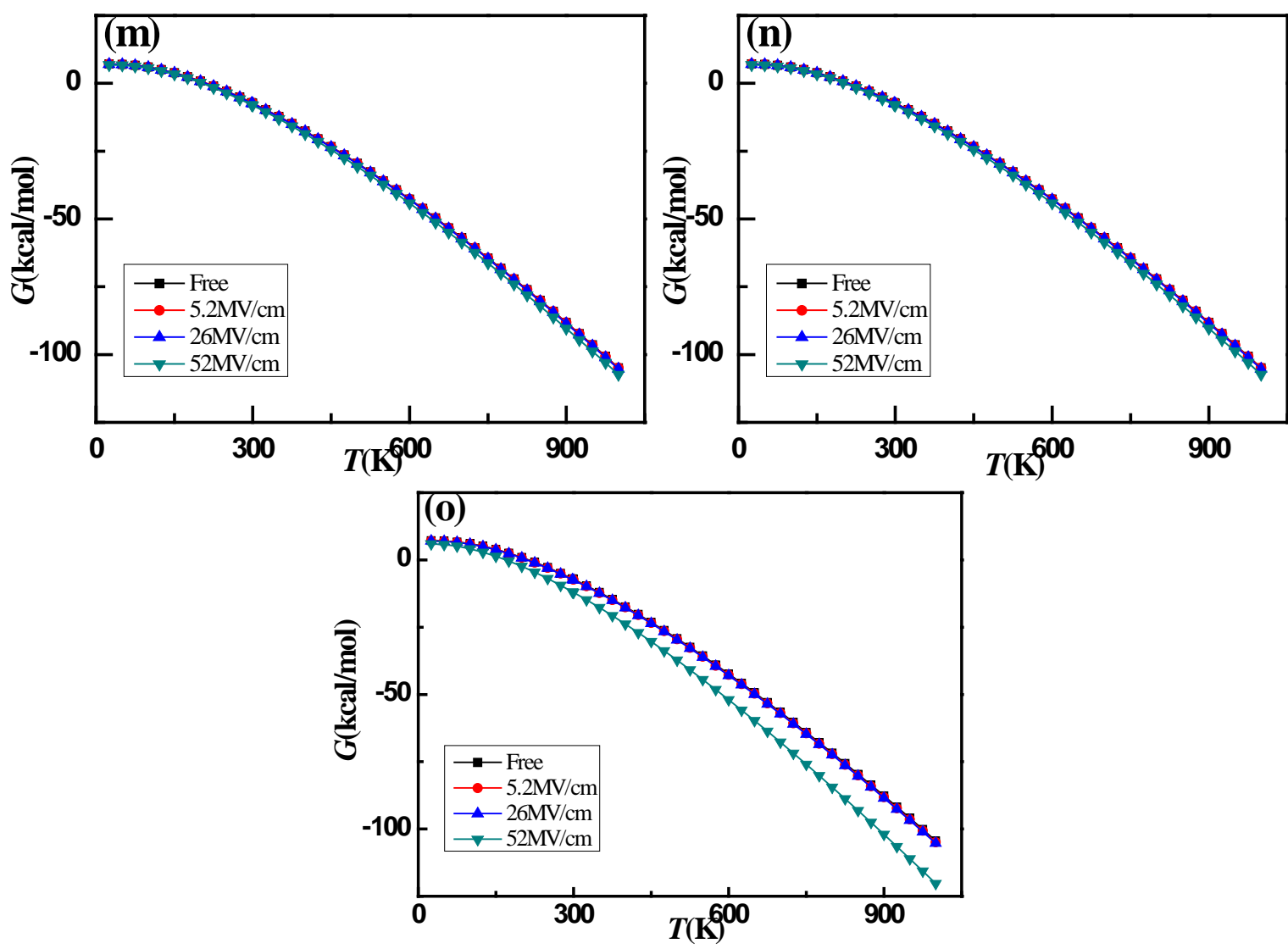

Fig. 2 Gibbs free energy curves of (a, b, c) the GPI zone, (d, e, f) GPII zone, (g, h, i) $\eta^{\prime}$ I phase, (j, k, l) $\eta^{\prime}$ II phase, and $(\mathrm{m}, \mathrm{n}, \mathrm{o}) \eta$ phase under electric field with its direction along $(\mathrm{a}, \mathrm{b}, \mathrm{c}) \mathrm{GPI}[100]_{\mathrm{GPI}}$, $[010]_{\mathrm{GPI}}$, and [001] $]_{\mathrm{GPI}}$ orientations, respectively; (d, e, f) GPII [100] $]_{\mathrm{GPII}},[010]_{\mathrm{GPII}}$, and [001] $]_{\mathrm{GPII}}$ orientations, respectively; (g, h, i) and (j, k, l) $\eta^{\prime}$ I and $\eta^{\prime}$ II $[10-10]_{\eta^{\prime}},[-1110]_{\eta^{\prime}}$, and $[0001]_{\eta^{\prime}}$ orientation, respectively; $(\mathrm{m}, \mathrm{n}, \mathrm{o}) \eta[10-10]_{\eta},[-1110]_{\eta}$, and $[0001]_{\eta}$ orientations, respectively.

\section{Effect of the External Electric Field on the Density of States}

Density of states has been studied to obtain deeper insight into the influence of the external electric field on phase transformation. The partial density of states (PDOS) of the GP zones, $\eta^{\prime}$ and $\eta$ phases has been calculated (shown in Fig. 3). With the electric intensity lower than $26 \mathrm{MV} / \mathrm{cm}$, the splitting of energy level only appears in $\eta^{\prime}$ phase with the electric field direction along $[0001]_{\eta^{\prime}}$ crystal orientation. The outer electrons of $\eta^{\prime}$ phase are partially excited to higher energy levels affected by external electric field. At the condition that the electric field direction is along the $[10-10]_{\eta^{\prime}}$ or $[-1110]_{\eta^{\prime}}$ crystal orientations, little $d$ orbital electrons are excited to higher energy levels with electric intensity lower than $26 \mathrm{MV} / \mathrm{cm}$. When the electric intensity approaching 52MV/cm, the PDOS of $\eta$ phase shows the similar feature, which coincides well with the result of Fig. 2(0). This reveals the anisotropy of the $\eta^{\prime}$ and $\eta$ phases in an external electric field.

As a result, the electrons of the $\eta$ ' phase are easier to be activated to higher energy levels than those of the GP zones, resulting in the larger dielectric constants of the $\eta^{\prime}$ phase than GP zones. The free energy for the formation of a nucleus formation with critical size is[26]

$$
\Delta G_{c}=\frac{16 \pi \sigma^{3}}{3\left[\left|\Delta G_{v}\right|+\frac{1}{2} E_{2}^{2}\left(\varepsilon_{2}-\varepsilon_{1}\right)\right]^{2}}
$$


where $\sigma$ is the interfacial energy, $\Delta G_{v}$ is the driving free energy, $E_{2}$ is the electric field, $\varepsilon_{1}$ and $\varepsilon_{2}$ are the dielectric constants of the matrix and precipitating phase, respectively. If $\varepsilon_{2}>\varepsilon_{1}, \Delta G_{c}$ is reduced compared with $\Delta G_{v}$, and nucleus formation or phase transformation is promoted by the applied electric field. If $\varepsilon_{2}<\varepsilon_{1}$, phase transformation is inhibited. Therefore, phase transformations under electric field are biased toward the phase which has higher dielectric constant than the parent phase. By applying an external electric field, phase transformation from the GP zones to the $\eta$ ' phase can be accelerated because the dielectric constant of the $\eta^{\prime}$ phase is higher than that of the GP zones.
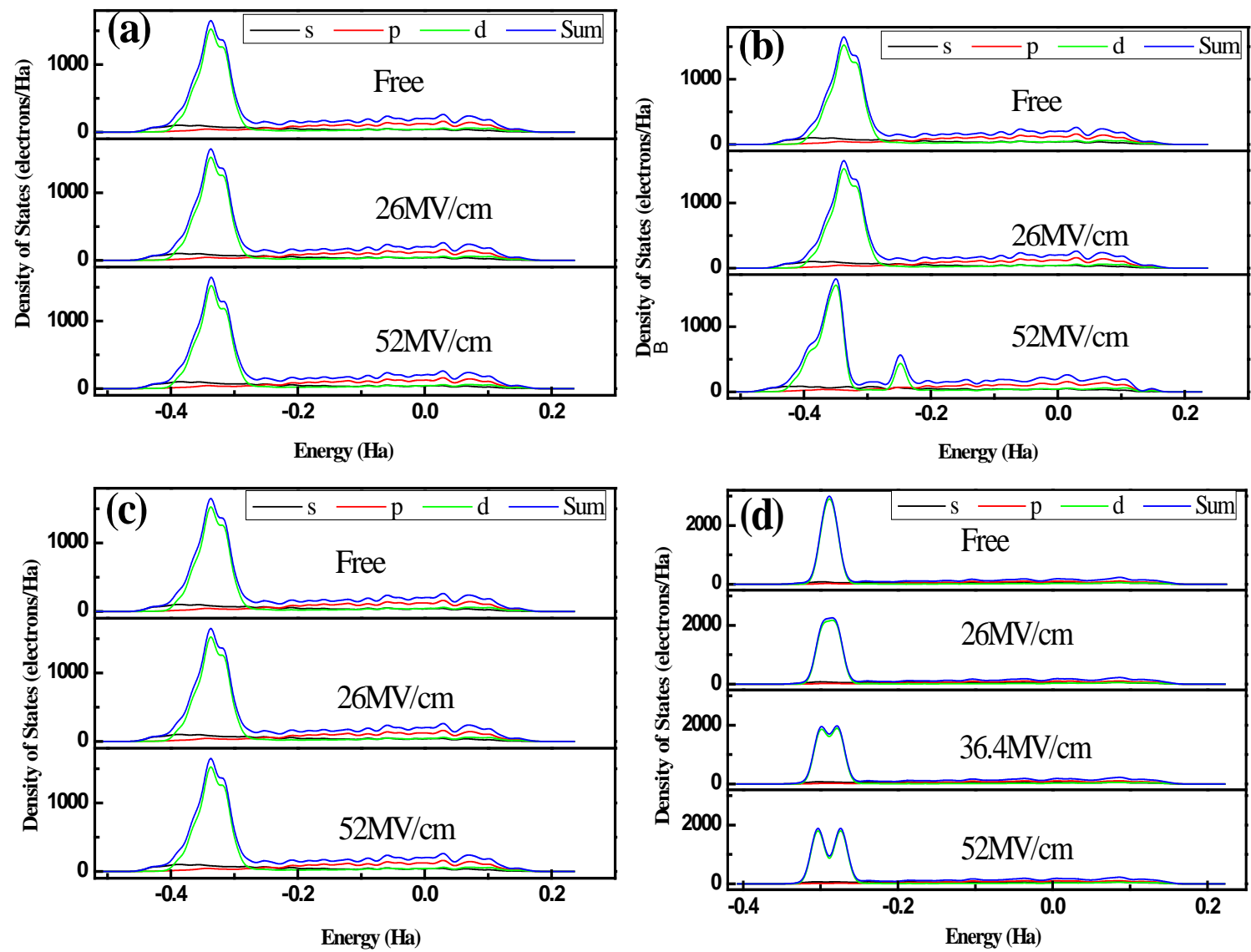

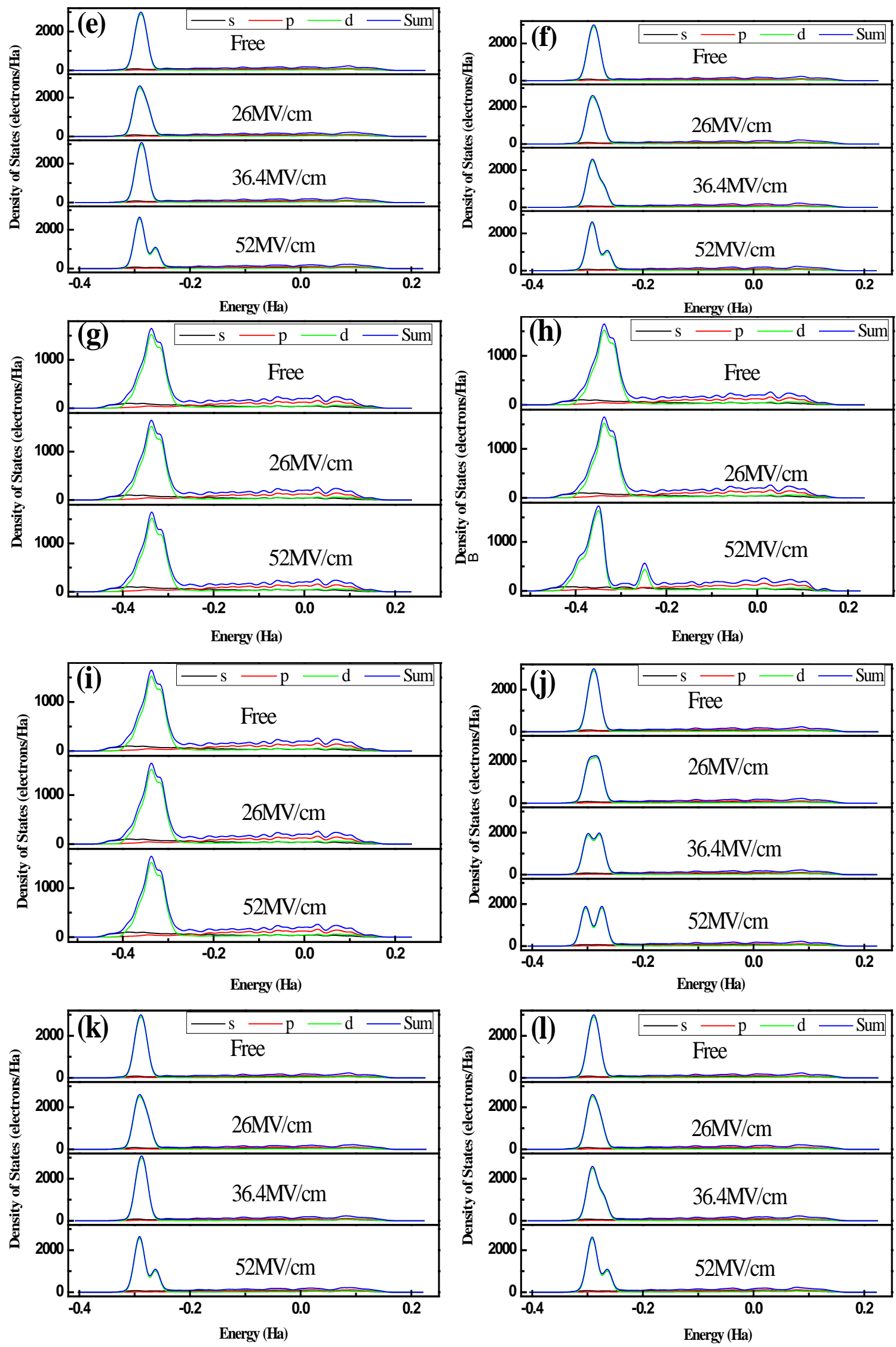

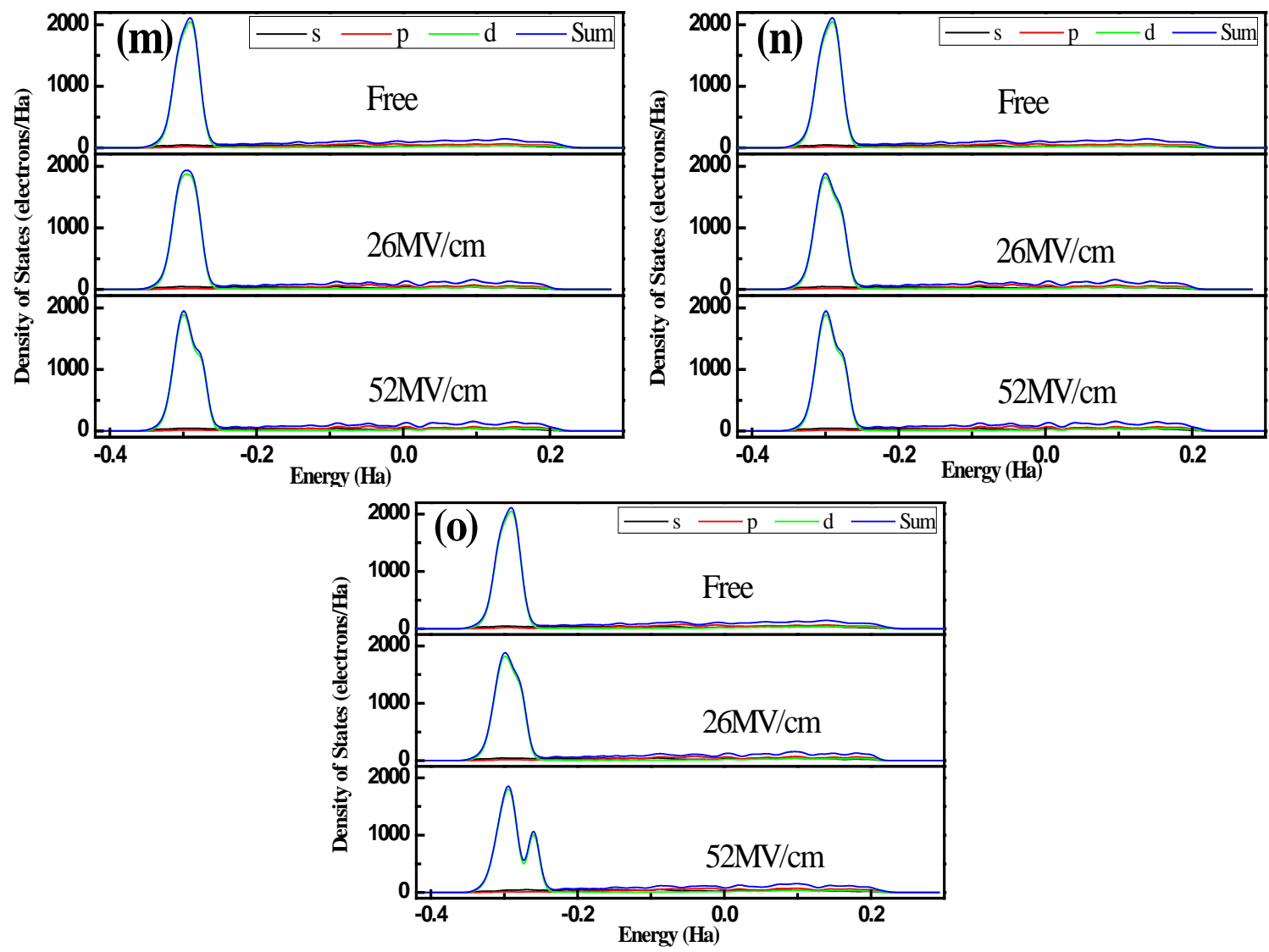

Fig. 3 PDOS of the zones and phases with different electric intensities for the (a, b, c) GPI zone with electric field direction along $[100]_{\mathrm{GPI}},[010]_{\mathrm{GPI}}$, and $[001]_{\mathrm{GPI}}$ orientations, respectively; (d, e, f) GPII zone with electric field direction along $[100]_{\mathrm{GPII}},[010]_{\mathrm{GPII}}$, and [001] $]_{\mathrm{GPII}}$ orientations, respectively; (g, h, i) and (j,k,l) $\eta^{\prime}$ I and $\eta^{\prime}$ II phase with electric field direction along [10-10 $]_{\eta^{\prime}}$ [ $[-1110]_{\eta^{\prime}}$, and $[0001]_{\eta^{\prime}}$ orientations, respectively; $(\mathrm{m}, \mathrm{n}, \mathrm{o}) \eta$ phase with electric field direction along $[10-10]_{\eta},[-1110]_{\eta}$, and

$[0001]_{\eta}$ orientations, respectively.

\section{Effect of External Electric Field on Vacancy}

Phase transformations must involve a type of diffusion process because solutes must be transferred from the Al matrix to the solute-rich zones and then transformed into different phases based on thermodynamic conditions[27]. One criterion of the complex mechanism is that solutes leading to non-equilibrium segregation at grain boundaries preferentially interact with vacancies[28]. Another criterion is that complexes must be thermodynamically stable or metastable. The latter has been discussed in Section 3.2. The effect of the external electric field on vacancies will be discussed below.

On the condition that the samples are treated as a solid solution, excessive vacancies may be frozen in the matrix during quenching before artificial aging. The vacancies act as a transmission path of the solute atoms[28]. Thus, the migration of vacancies may influence the distribution of the precipitations.

The specimens aged with an electric field are always connected to a positive terminal of the high-voltage power supply; the surface of the specimens is therefore charged with positive charge. According to Liu, under the conditions of aging treatment with an applied electric field, the presence of a charge on the defect may occur due to the perturbation caused by the external electric field[29]. The applied field can create a charged surface layer in metallic material, and the surface charge can interact with the charged defects, particularly vacancies. When they approach the surface, they create an additional vacancy flux (shown in Fig. 4(a)). 

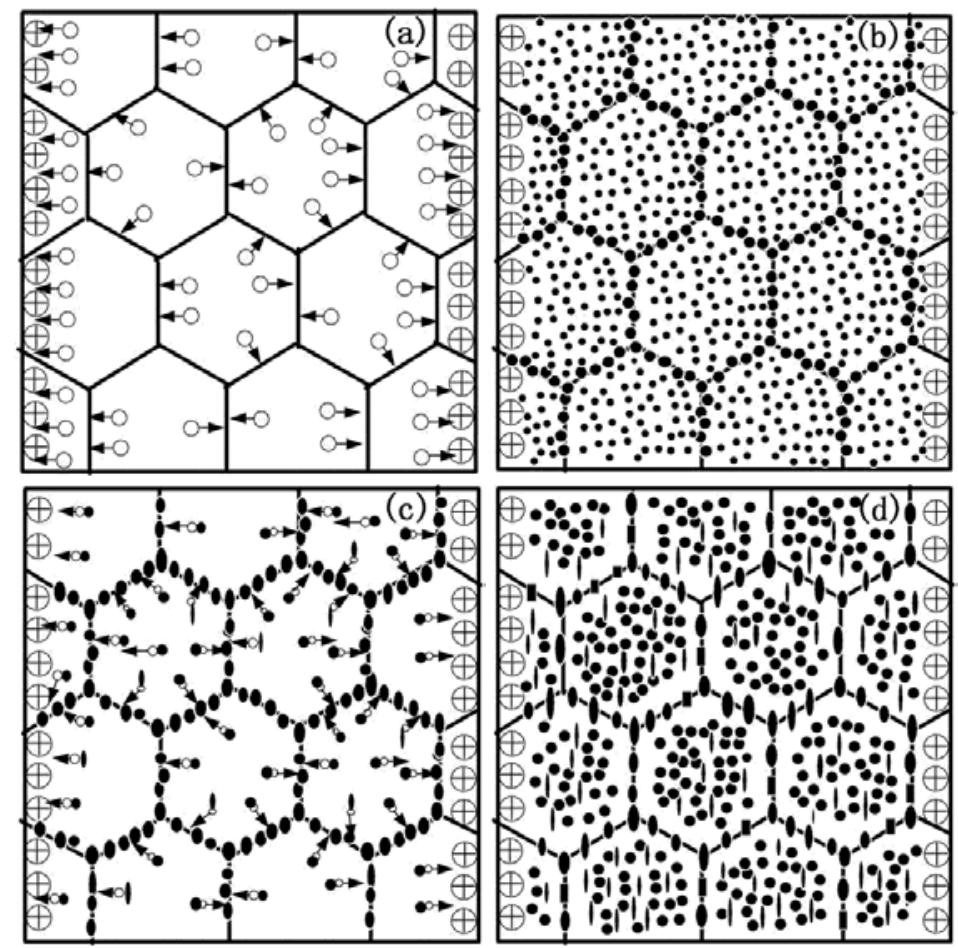

Fig. 4 Model of the mechanism for the effect of electric field on vacancy flow and precipitation during aging. (०) vacancy; $(\oplus)$ surface charge; $(\bullet)$ precipitate.

The nucleation of precipitate in the matrix is uniformly dispersed at the beginning of the aging treatment because of the high degree of supersaturation of solute atoms and vacancies. The grain boundaries also provide favorable conditions for nucleation (Fig. 4(b)). According to Girifalco and Herman's solute-vacancy complexes theory, once solute atoms are incorporated into the precipitates, vacancies are liberated and then return back to the matrix where they can interact with other solute atoms and bring them to the precipitates[27]. Diffusion occurs in the direction opposite to that of vacancy flows according to the principle of cyclic transport of solute atoms by vacancies[28]. Based on the orientation precipitation of the $\eta^{\prime}$ precipitation concluded from the thermodynamics calculation in Section 3.4, the solute atoms tend to precipitate at vacancy sites along the direction of the electric field. The vacancies shift step by step to the grain boundary or dislocation and sink owing to the oriented transition (Fig. 4(c)). The presence of vacancy aggregation along the grain boundary is therefore promoted during the growth of the precipitates. The grain boundary becomes more convenient to the migration of solute atoms and more beneficial to the growth of the precipitates. Thus the solute atoms are dragged by the nearby vacancies, which is beneficial for the precipitates along grain boundary to grow up. Meanwhile, the precipitation free zone (PFZ) is broadened (Fig. 4(d)).

Phase transformations from GP zones to $\eta$ ' phase during the aging treatment with an electric field can be accelerated based on the calculations for thermodynamics. So aging time should be shortened in the absence of an electric field. Compared with the aging treatment without an electric field, the microstructure with suitable external electric field may contain fine and disperse precipitates in the grain interior, combined with discontinuous and coarse precipitates along the grain boundary, accompanied with appropriate PFZ. The microstructure is beneficial to the overall properties of the alloy, especially to fatigue crack propagation resistance and stress corrosion resistance[2,4,29].

\section{Conclusions}

When aged in the presence of an electric field, the Al-Zn-Mg-Cu alloy may achieve optimized microstructure based on vacancy mechanism and thermodynamics calculation results. At the condition of aging with an applied electric field lower than $26 \mathrm{MV} / \mathrm{cm}$, the orientation growth of $\eta^{\prime}$ 
phase may be induced during aging with an external electric field. Phase precipitation with the $[0001]_{\eta^{\prime}}$ crystal orientation along the direction of the electric field may be stimulated because the $\eta^{\prime}$ phase's Gibbs free energy effectively decreases with the electric field direction along the [0001] $\eta_{\eta^{\prime}}$ crystal orientation. Further, the calculation of density of states gives explanation to the different responses of the GP zones, $\eta^{\prime}$ and $\eta$ phases to the external electric field.

\section{Acknowledgment}

This work was financially supported by the Fundamental Research Funds for the Central Universities (XDJK2014C008 and SWU115068), the Chongqing scientific and technological projects (CSTC2014JCYJYS0001,CSTC2012GGYS0001), and by Program for the Youth Talent in Science and Technology of Chongqing(CSTC2014KJRC-QNRC50006).

\section{References}

[1] H. Conrad, Effect of interstitial solutes on the strength and ductility of titanium, Mater. Trans. 46 (2005) 1083-1087.

[2] M. Z. Zhou, D. Q. Yi, H.Q. Liu, W. J. Liu, F. Zheng, Enhanced fatigue crack propagation resistance of an $\mathrm{Al}-\mathrm{Cu}-\mathrm{Mg}$ alloy by artificial aging under influence of electrical field, Mater. Sci. Eng. A 527 (2010) 4070-4075.

[3] J. Z. Wang, J. G. Qi, Z. F. Zhao, H. S. Guo, T. Zhao, Effects of electric pulse modification on liquid structure of Al-5\%Cu alloy, T. Nonferr Metal Soc. 23 (2013) 2792-2796.

[4] B. Liu, Z. Chen, Y. X. Wang, X. N. Wang, The effect of an electric field on the mechanical properties and microstructure of Al-Li alloy containing Ce, Mater. Sci. Eng. A 313 (2001) 69-74.

[5] A. A. Shibkov, A. A. Denisov, M. A. Zheltov, A. E. Zolotov, M. F. Gasanov, The electric current-induced suppression of the Portevin-Le Chatelier effect in Al-Mg alloys, Mater, Sci. Eng. A 610 (2014) 338-343.

[6] B. Liu, Z. L. Zhao, Y. X. Wang, Z. Chen, The solidification of Al-Cu binary eutectic alloy with electric fields, J. Cryst. Growth 271 (2004) 294-301.

[7] W. Liu, J. Z. Cui, A study on the ageing treatment of 2091 Al-Li alloy with an electric field, J. Mater. Sci. Lett. 16 (1997) 1410-1411.

[8] J. J. Zhang, Z. Chen, Y. X. Wang, B. Liu, Gibbs free energy calculation of Al-Cu-Li alloy with the effect of electric field from electron level, J. Alloy Compd. 457 (2008) 526-531.

[9] M. B. Javan, First principles study of the electronic and optical properties of GaAs nanoparticles under the influence of external uniform electric field, Phys. Lett. A 376 (2012) 3241-3247.

[10] L. Si, Z. Y. Jiang, B. Zhou, W. Z. Chen, First-principles study of martensitic phase transformation of TiRh alloy, Physica B 407 (2012) 347-351.

[11] K. Y. Chen, L. M. Cheng, Alloying solid solution strengthening of Fe-Ga alloys: a first-principles study, J. Phys. D Appl. Phys., 40 (2007) 3268-3270.

[12] D. Zhou, J. Liu, S. Xu, P. Peng, Thermal stability and elastic properties of $\mathrm{Mg}_{2} \mathrm{X}(\mathrm{X}=\mathrm{Si}, \mathrm{Ge}, \mathrm{Sn}$, $\mathrm{Pb}$ ) phases from first-principle calculations, Comput. Mater. Sci. 51 (2012) 409-414.

[13] S. A. Sabeti, M. Soleymani, M. Panjepour, G. Aryanpour, Thermodynamic study of grain growth in nanocrystalline metals and its simulation by molecular dynamics, Comput. Mater. Sci. 50 (2011) 2865-2871.

[14] A. Putrino, D. Sebastiani, M. Parrinello, Generalized variational density functional perturbation theory, J. Chem. Phys. 113 (2000) 7102-7109.

[15] Z.W. Huang, Y.H. Zhao, H. Hou, P.D. Han, Electronic structural, elastic properties and thermodynamics of $\mathrm{Mg}_{17} \mathrm{Al}_{12}, \mathrm{Mg}_{2} \mathrm{Si}$ and $\mathrm{Al}_{2} \mathrm{Y}$ phases from first-principles calculations, Physica. $\mathrm{B}$, 407 (2012) 1075-1081.

[16] L. K. Berg, J. Gjфnnes, V. Hansen, X. Z. Li, M. Knutson-wedel, G. Waterloo, D. Schryvers, L. R. Wallenberg, GP-zones in Al-Zn-Mg alloys and their role in artificial aging, Acta Mater., 49 (2001) 
3443-3451.

[17] C. M. Li, Z. Q. Chen, S. M. Zeng, N. P. Cheng, T. X.Chen, Intermetallicphase formation and evolution during homogenization and solution in Al-Zn-Mg-Cu alloys, China Tech. Sci., 56 (2013) 2615-2876.

[18] X. B. Yang, J. H. Chen, J. Z. Liu, P. Liu, F. Qin, Y. L. Cheng, C. L. Wu, Spherical constituent particles formed by a multistage solution treatment in Al-Zn-Mg-Cu alloys, Mater. Charact. 83 (2013) 79-88.

[19] J. H. Auld, S. M. Cousland, The transition phase $\eta^{\prime}$ in Al-Zn-Mg alloys', Scripta Metal. 5 (1971) 765-769.

[20] X. Z. Li, V. Hansen, J. Gj申nnes, L. R. Wallenberg, HREM study and structure modeling of the $\eta^{\prime}$ phase, the hardening precipitates in commercial Al-Zn-Mg alloys, Acta Mater. 47 (1999) 2651-2659. [21] S. P. Ringer, K. Hono, Microstructural evolution and age hardening in aluminium alloys: Atom probe field-ion microscopy and transmission electron microscopy studies, Mater. Charact. 44 (2000) 101-131.

[22] G. Wandahl, A. N. Christensen, Occurrence of Extinction Correlated with Crystal Growth Mode for Crystals of $\mathrm{Pd}_{3}$ Ce and $\mathrm{MgZn}_{2}$, Acta Chem. Scand. 43 (1989) 296-297.

[23] Y. Komura, K. Tokunaga, Structural studies of stacking variants in Mg-base Friauf-Laves phases, Acta Cryst. 36 (1980) 1548-1554.

[24] J. B. Friauf, The crystal structure of magnesium di-zincide, Phys. Rev. 29 (1927) 34-40.

[25] T. Ohba, Y. Kitano, Y. Komura, The charge-density study of the Laves phases, $\mathrm{MgZn}_{2}$ and $\mathrm{MgCu}_{2}$, Acta Cryst. C40 (1984) 1-5.

[26] Liu W., Liang K.M., Zheng Y.K., Gu S.R, Chen H, The effect of an electric field on the phase separation of glasses, J. Phys. D Appl. Phys. 30 (1997) 3366-3370.

[27] L. A. Girifalco, H. Herman, A model for the growth of Guinier-Preston zones-the vacancy pump, Acta Metal. 13 (1965) 583-700.

[28] T. D. Xu, Non-equilibrium grain-boundary segregation kinetics, J. Mater. Sci. 22 (1987) 337-345.

[29] W. Liu, K. M. Liang, Y. K. Zheng, J. Z. Cui, Study of the diffusion of Al-Li alloys subjected to an electric field, J. Mater. Sci. 33 (1998) 1043-1047. 